\title{
Failure Analysis of Pharmaceutical Clamp Ferrules
}

\author{
Jian Feng $(\mathbb{1}$
}

Submitted: 2 March 2020/Published online: 6 August 2020

(C) The Author(s) 2020

\begin{abstract}
The purpose of this case study is to determine the cause of failure of DIN 1.4435 BN2 (AISI 316L with very low ferrite contents) clamp ferrules applied in pharmaceutical systems. Leakage was observed during operation in the clamp pipe connections of the ultra-pure fluid delivery systems. The surface of clamp ferrules showed remarkable discoloration and cracking. It was identified that the failure was caused by defects related to the autogenous laser conduction welding procedures. The intragranular cellular welded structures, which solidified with austenite as the primary product of solidification, showed a complete absence of hot cracks, minor delta ferrite, and minimum microsegregation. The welded components failed eventually owing to unstable welding profiles and significant porosity. Recommendations were given to prevent the recurrence of similar failures.
\end{abstract}

Keywords Failure analysis - Austenitic stainless steel · Welding metallurgy · Metallography · Fractography ·

Microhardness · Porosity

\section{Introduction}

The particular demands of pharmaceutical systems place many requirements on welded components used in the production environment. The piping connections with improved surface cleanliness must be highly corrosion resistant to withstand the cleaning regimes essential to guarantee drug purity and integrity. These requirements

\footnotetext{
J. Feng $(\bowtie)$

Centre of Materials Engineering, Heilbronn University,

Max-Planck-Str. 39, 74081 Heilbronn, Germany

e-mail: jian.feng@web.de; jian.feng@hs-heilbronn.de
}

have led to the selection of type AISI 316L stainless steel for most pharmaceutical and biotechnological applications. The delta-ferrite content in $316 \mathrm{~L}$ is further restricted in the Mo-, Ni-, and Cu-rich grade DIN 1.4435 BN2, since delta ferrite can be detrimental in certain chemical environments and some transformation products of delta ferrite can drastically deteriorate the corrosion resistance of welds [1].

The piping connections of $1.4435 \mathrm{BN} 2$ are often joined by autogenous laser conduction welding (ALCW), which offers several compelling advantages. ALCW can be easily automated and applied to thin-wall parts. Sound strength of welds with clean appearances can be obtained by ALCW without any filler material. The inherent rapid solidification makes the use of ALCW very attractive, as the obtained microstructures with adapted solidification behavior, minimum segregation, and fine grain sizes can often improve the mechanical properties of welds [2].

In the present case, clamp connections of $1.4435 \mathrm{BN} 2$ pipes used in pharmaceutical systems were orbitally welded together by ALCW without purging in the air. Electropolishing was subsequently conducted on the top surfaces in order to eliminate the distortion. Leakage was observed during operation on the clamp pipe connections of the ultra-pure fluid delivery systems. The clamp connections were finished according to the DIN 32676 specification. The seals remained securely tight, whereas the clamp ferrules went defective. The present study determines the causes of the defects that led to the failure of the clamp ferrules. It is based on chemical analysis, visual examination, metallography, microhardness mapping, welding profile analysis, and fractography of the welds. Possible solutions for future production are suggested in order to prevent or reduce the initiation of defects that occurred during the ALCW of the clamp connections. 


\section{Material Testing Results}

\section{Chemical Analysis}

As listed in Table 1, the chemical composition as analyzed by means of glow discharge optical emission spectroscopy (GDOES, Spectruma GDA750) and X-ray fluorescence spectrometry (XRF, Olympus Innov-X) confirmed that the material of the clamp ferrules met the Basler II standard of Basler Chemische Industrie (BCI) for 1.4435 BN2 (X2CrNiMo18-14-3 or AISI 316L). The correspondent plot in the WRC-1992 diagram [3] calculated from the chemical composition, fields of solidification modes, and constant lines of delta-ferrite content (ferrite number, FN) at ambient temperature are illustrated in Fig. 1. An apparent higher delta-ferrite content can be determined graphically via the WRC-1992 diagram than the value estimated by means of the Schaeffler diagram 1949. Both values are far less than $5 \%$, the approximate lower limit to resist the solidification cracking. In fact, a slightly raised delta-ferrite content (but still within the scope of Basler II standard, i.e., delta-ferrite content $\leq 0.5 \%$ ) is indeed desired in ALCW [4]. During solidification, delta ferrite has a greater solubility than austenite for harmful elements such as sulfur and phosphorus and thus reduces the segregation of these elements as well as the risk of the solidification cracking at the grain boundary. Yet $1.4435 \mathrm{BN} 2$ steel used in the present study can be well welded on account of the controlled contents of sulfur and phosphorus. An approx. $0.5 \%$ of delta-ferrite content at ambient temperature of the 1.4435 BN2 steel used was estimated by magnetic measurements (Feritscope, Fischer FMP30).

\section{Visual Examination}

The technical drawing of clamp ferrules is shown in Fig. 2. The manufacturing tolerances met the DIN 32676 specification. The designed maximal operating pressure of the piping connections is 25 bar. The locations of welds and brazing joints are highlighted. As the ALCW welds were responsible for the pressure resistance and leak tightness of the clamp connections, the examination was focused on the ALCW welds. As shown in Fig. 3a, faint blue discoloration or heat tint, which has a direct bearing on the corrosion resistance of welds, was observed on the electropolished surface of weld seams. Largely reduced by electropolishing, the discoloration was yet heavy and nonuniform. The observed discoloration levels were much higher than sample number 3 according to the AWS D18 standard even after electropolishing and, thus, unacceptable for pharmaceutical systems. Remarkable cracking was observed within the discolored region (Fig. 3b), which

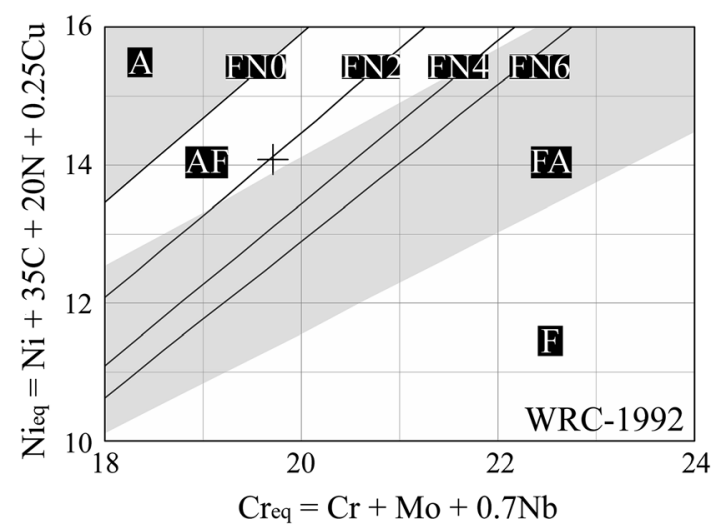

Fig. 1 WRC-1992 diagram with fields of solidification modes separated by dark-bright contrast and constant (solid) lines of deltaferrite content at ambient temperature. FN indicates the ferrite number, A austenitic solidification mode, AF austenitic-ferritic solidification mode, FA ferritic-austenitic solidification mode, and F ferritic solidification mode, respectivelyPRE indicates the pitting resistance equivalent number, $\mathrm{Cr}_{\mathrm{eq}}$ the $\mathrm{Cr}$-equivalent, and $\mathrm{Ni}_{\mathrm{eq}}$ the $\mathrm{Ni}$ equivalent, respectively

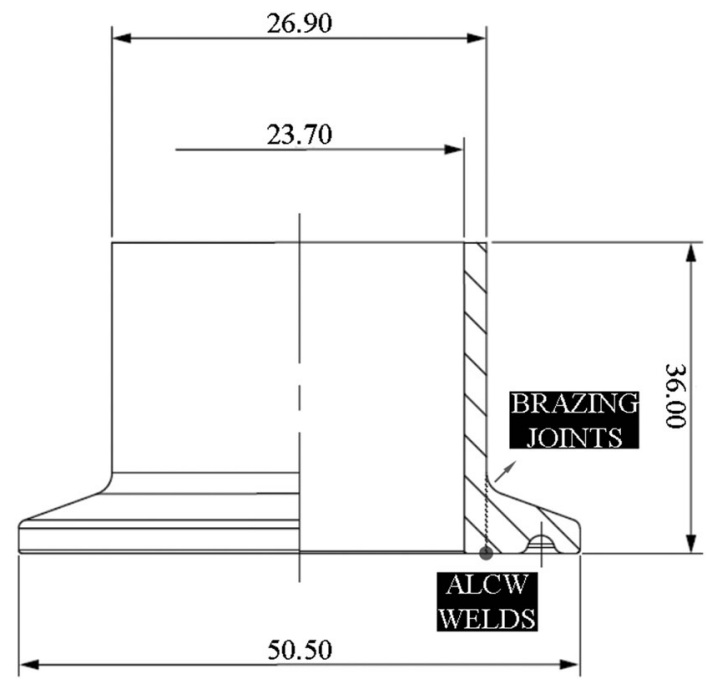

Fig. 2 Technical drawing of clamp ferrules with highlighted ALCW welds (in $\mathrm{mm}$ )

Table 1 Chemical composition of materials used (in wt.\%)

\begin{tabular}{lccccccccccc}
\hline $\mathrm{C}$ & $\mathrm{Si}$ & $\mathrm{Mn}$ & $\mathrm{P}$ & $\mathrm{S}$ & $\mathrm{Cr}$ & $\mathrm{Ni}$ & $\mathrm{Mo}$ & $\mathrm{Cu}$ & $\mathrm{N}$ & $\mathrm{PRE}$ & $\mathrm{Cr} \mathrm{rq}_{\mathrm{eq}} / \mathrm{Ni}_{\mathrm{eq}}$ \\
\hline 0.017 & 0.67 & 1.43 & 0.018 & 0.017 & 17.16 & 12.70 & 2.55 & 0.35 & 0.035 & 26.1 & 1.40 \\
\hline
\end{tabular}

PRE indicates the pitting resistance equivalent number, $\mathrm{Cr}_{\mathrm{eq}}$ the $\mathrm{Cr}$-equivalent, and $\mathrm{Ni}_{\mathrm{eq}}$ the Ni-equivalent, respectively 
could be responsible for the leakage. The cracking largely free of corrosion products was also observed on the unused parts from the same batch. By combining the results of fractographic investigations below, it is concluded that the discoloration is not directly related to the cracking.

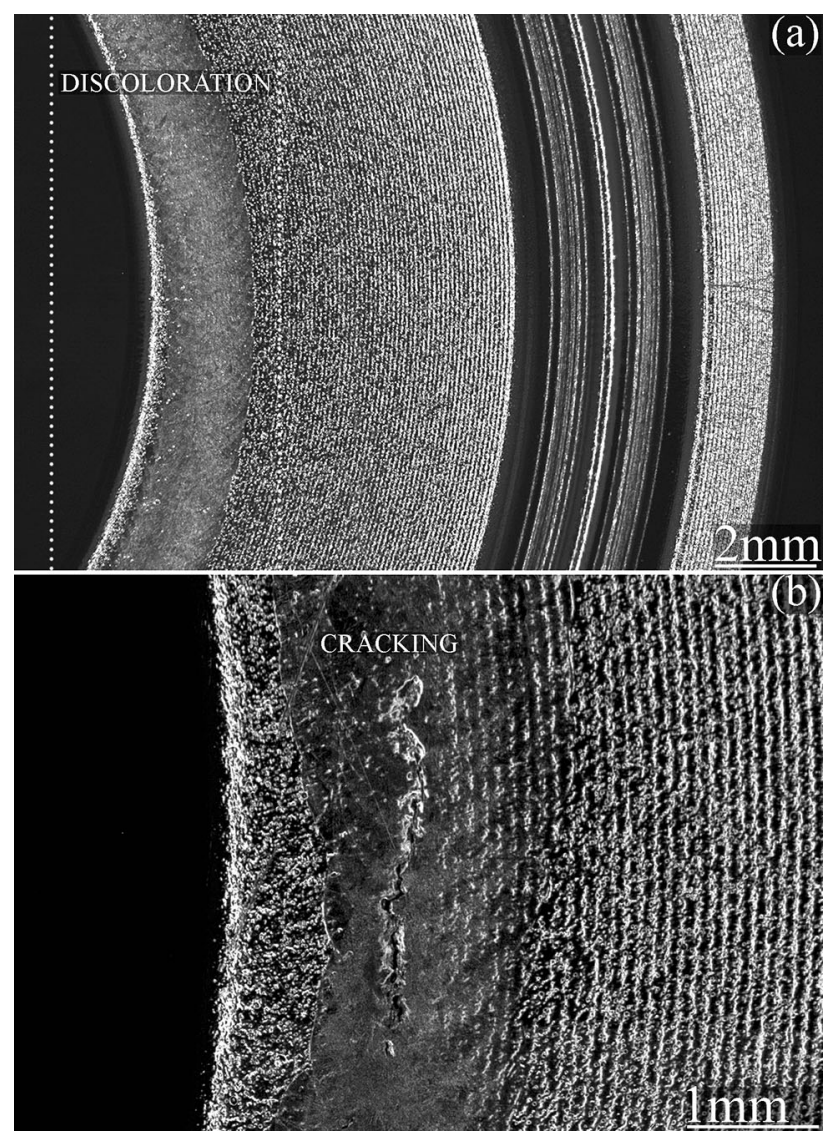

Fig. 3 (a) Faint blue discoloration (heat tint) and (b) remarkable cracking on the surface of weld seams after electropolishing
Metallography

The solidification structure of the $1.4435 \mathrm{BN} 2$ weld seams characterized by an optical microscope (OM, Olympus GX51) is shown in Figs. 4 and 5. A predominantly intragranular cellular and nearly fully austenitic solidification/ segregation network is visible. The intragranular cellular network [5], oriented toward the local thermal gradient inside the molten pool, exists in every columnar grain and has a cell size of approx. $5 \mu \mathrm{m}$. The microstructure is formed as a result of rapid solidification (with moderate undercooling) due to very high cooling rates encountered in ALCW. The network can be related to compositional fluctuations (especially $\mathrm{Cr}$, Mo, and S [6]), and its growth is controlled by the heat flow, i.e., $G / R$ ratio $(G=$ temperature gradient in the liquid, $R=$ solidification rate). The metallographic examination could not qualitatively reveal the ferrite content in these regions although magnetic measurement showed approx. $0.5 \%$ of delta ferrite on average. The weld seams exhibited predominantly austenitic-ferritic (AF) modes of solidification, which is consistent with the descriptions given by the WRC-1992 diagram (Fig. 1). It is apparent in Fig. 5 that the migration of the solidification boundaries is largely free and completely divorced from the segregation patterns formed during solidification. Liquation and microcracking at grain boundaries are thus less likely [7]. Networks of microcracks were observed neither in base metal nor in welds. The possibility of stress corrosion cracking is denied, and there was no sign of embrittlement.

Microhardness Mapping, Welding Profile Analysis, and Fractography

Microhardness mapping at a load of $10 \mathrm{~g}$ was performed on the longitudinal sections of the weld seams. Unexpected weak spots (porosity) were detected within the weld beads,

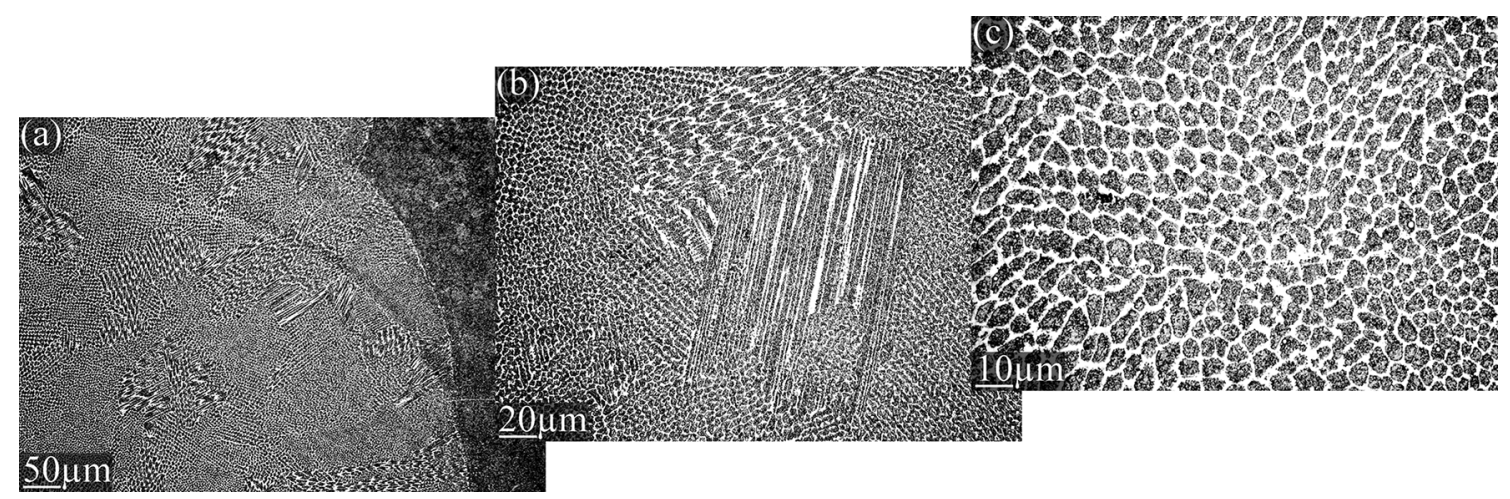

Fig. 4 Micrographs (transverse section, parallel to the laser scan direction) of $1.4435 \mathrm{BN} 2 / 316 \mathrm{~L}$ stainless steel welded by autogenous laser conduction welding showing predominantly intragranular cellular networks: (a) overview of the weld seam, (b) the intragranular cellular network and (c) the intragranular cellular network at the intersection between different subdomains 
though merely one single pore is visible on the section as shown in Fig. 6. The weld seams were generally enhanced by ALCW, whereas these spots were even weaker than the base metal. The morphology/geometry of the weld beads

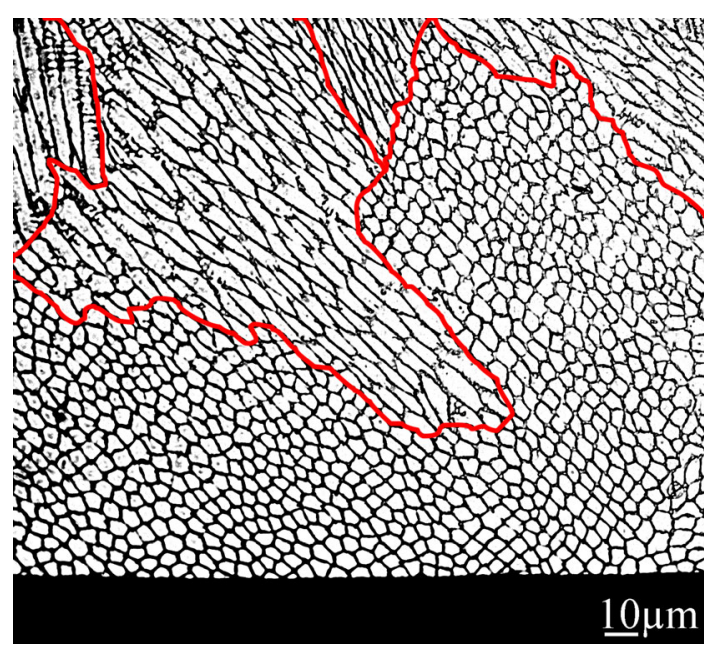

Fig. 5 Migration of the solidification boundaries (shown in red) divorced from the segregation patterns (Color figure online) was characterized by the penetration-depth profile, the profile of full width at half maximum (FWHM), and the depth/width ratio profile. As shown in Fig. 7, the distribution of all these three profiles is significantly unsymmetrical, indicating that ALCW without weld purging was keenly unstable. To reveal the nature of the weak spots in the microhardness mapping, parts of weld seams were cut out from clamp ferrules and pulled through transversely by tensile forces. The fractographic analysis was performed by a scanning electron microscope (SEM, JEOL JSM6510). It is shown in Fig. 8 that a network of pores was observed along the weld seams, i.e., high porosity, which is possibly responsible for the cracking of the welds.

\section{Discussion}

ALCW beads typically present a semi-spherical geometry with penetration lower than the bead width. In pure conduction welding, the power density should be high enough to ensure melting but below the vaporization threshold of the base metal. The penetration depth (as shown in Fig. 7)

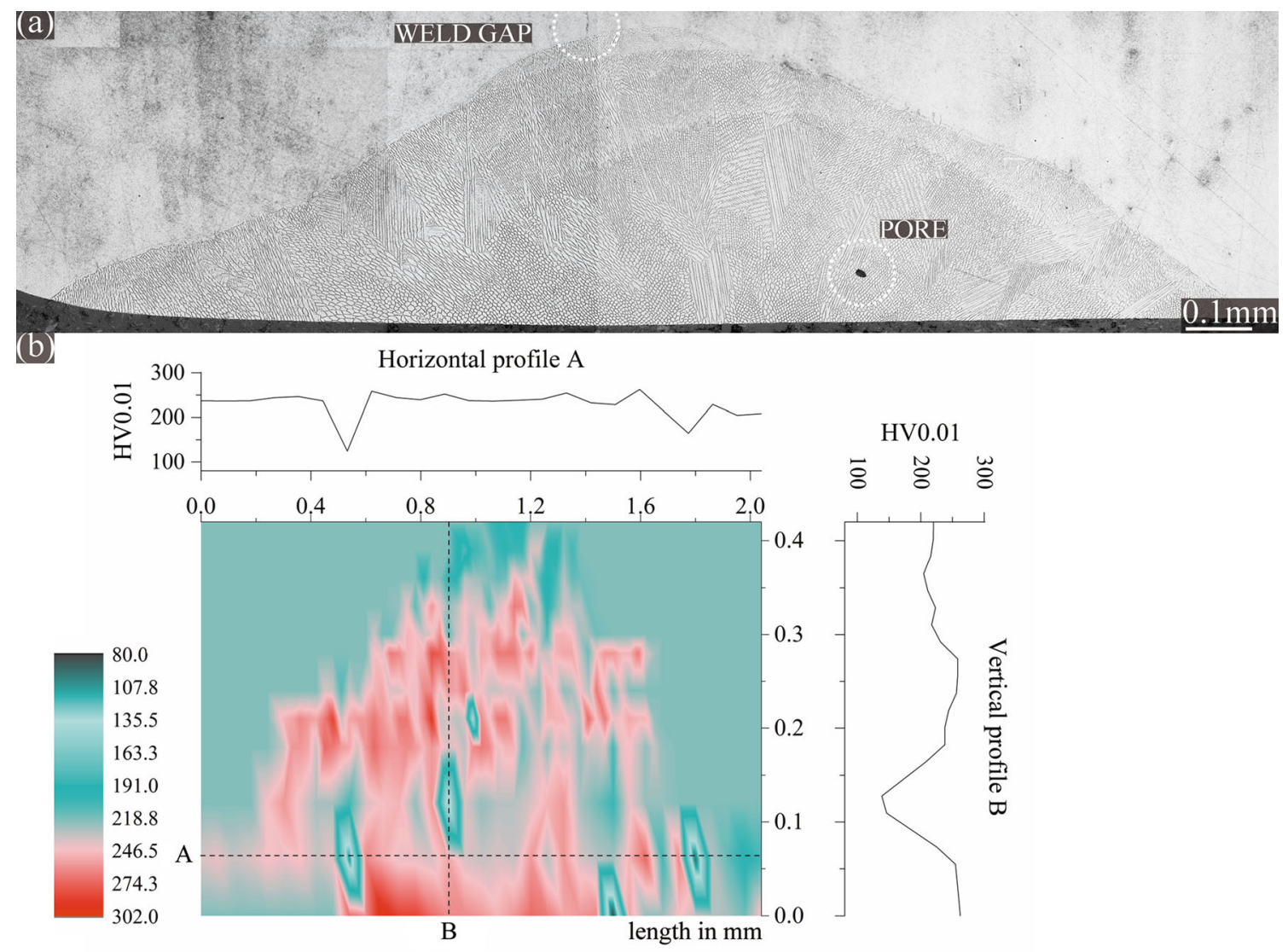

Fig. 6 Micrographs (longitudinal section, normal to the laser scan direction) of 1.4435 BN2/316L stainless steel welded by autogenous laser conduction welding: (a) the intragranular cellular network, and (b) correspondent microhardness distribution 
is very dependent on the interaction time, which should be long enough to allow for sufficient heat conduction. By increasing power density and using different beam diameters/interaction times, a transition from conduction mode to keyhole mode can take place [8]. The keyhole regime is more common due to its narrow weld profiles with high aspect ratio and, therefore, high productivity with low distortions. However, the vaporization, which is the inherent feature of the keyhole regime, increases the like-

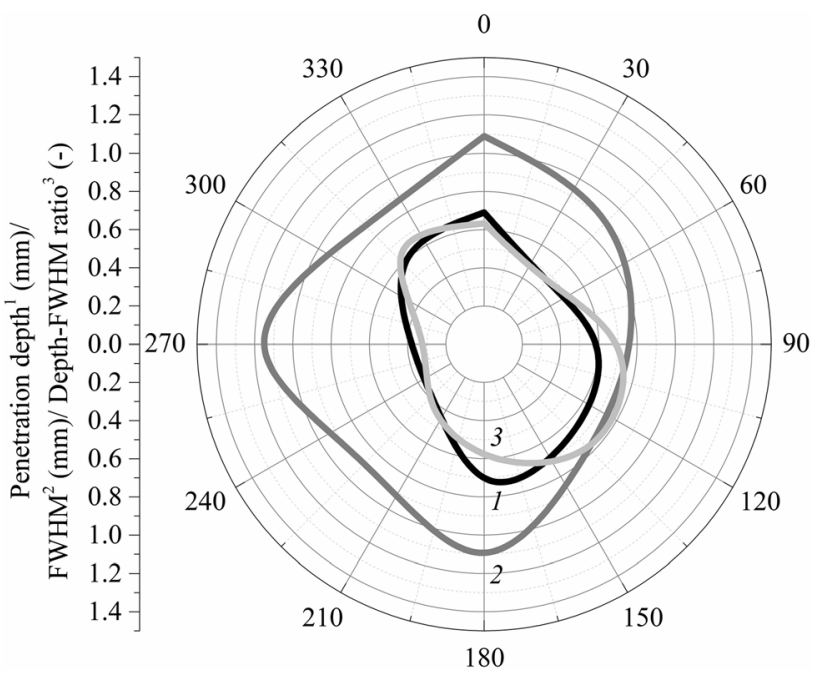

Fig. 7 The penetration-depth profile, the profile of full width at half maximum (FWHM), and the depth/width ratio profile of weld seams without purging lihood of pores. The evidence of remarkable vaporization in the present case is given by a close-up shot of the rippling internal surface represented in Fig. 8. After Ramos et al. [9], the rippling surface attains a sinusoidal shape having a characteristic wavelength, which is a result of the surface relaxation driven by interactions between gravity, surface curvature, and surface tension gradient. Without purging, a laser-induced plume can glow up and the incident laser beam can be defocused, deflected, refracted, and/ or inclined [10]. This leads to unstable molten pools and further increases the likelihood of pores.

\section{Conclusions and Recommendations}

In summary, $1.4435 \mathrm{BN} 2$ clamp ferrules welded by autogenous laser conduction welding exhibited predominantly intragranular cellular structures, solidified with austenite as the primary product of solidification, and showed a complete absence of hot cracks with minor delta-ferrite content and minimum microsegregation. It has been shown that the base metal was heavily vaporized due to high power density during the welding in the air. The incident laser beam was disturbed by the laser-induced plume resulting in unstable welding profiles. The unstable molten pools and the remarkable vaporization together led to high porosity and remarkable cracking in welds. In view of the above, to prevent the recurrence of similar failures, the vaporization should be avoided by a better combination of power density, beam diameter, and interaction time. Weld purging

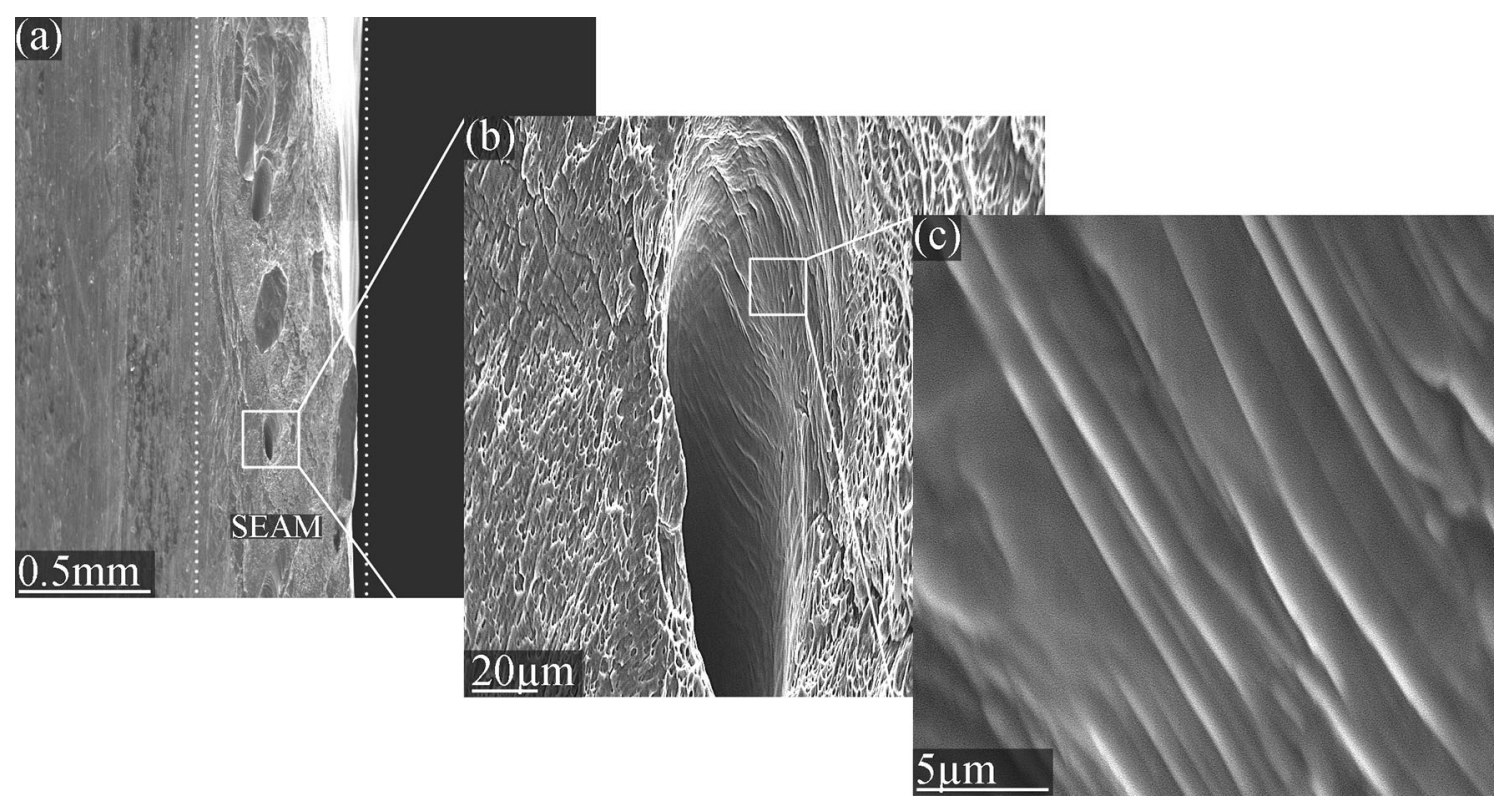

Fig. 8 Fractographs of $1.4435 \mathrm{BN} 2$ stainless steel welded by autogenous laser conduction welding. Weld seams were transversely pulled to fracture to identify the porosity: (a) overview of the weld seam, (b) a close-up shot of a pore, and (c) a close-up shot of the rippling pore surface 
with argon is recommended to make sure the cleanliness and stability of autogenous laser conduction welding.

\section{Acknowledgment Open Access funding provided by Projekt} DEAL.

Open Access This article is licensed under a Creative Commons Attribution 4.0 International License, which permits use, sharing, adaptation, distribution and reproduction in any medium or format, as long as you give appropriate credit to the original author(s) and the source, provide a link to the Creative Commons licence, and indicate if changes were made. The images or other third party material in this article are included in the article's Creative Commons licence, unless indicated otherwise in a credit line to the material. If material is not included in the article's Creative Commons licence and your intended use is not permitted by statutory regulation or exceeds the permitted use, you will need to obtain permission directly from the copyright holder. To view a copy of this licence, visit http://creativecommons. org/licenses/by/4.0/.

\section{References}

1. T. Wegrzyn, Delta ferrite in stainless steel weld metals. Weld. Int. 6(9), 690-694 (1992)

2. J.M. Vitek, A. Dasgupta, S.A. David, Microstructural modification of austenitic stainless steels by rapid solidification. Metall. Trans. A 14(9), 1833-1841 (1983)
3. D.J. Kotecki, T.A. Siewert, WRC-1992 constitution diagram for stainless steel weld metals: a modification of the WRC-1988 diagram. Weld. J. 71(5), 171-178 (1992)

4. Y. Cui, C.D. Lundin, Evaluation of initial corrosion location in E316L austenitic stainless steel weld metals. Mater. Lett. 59(12), 1542-1546 (2005)

5. Y. Zhong, L.F. Liu, S. Wikman, D.Q. Cui, Z.J. Shen, Intragranular cellular segregation network structure strengthening $316 \mathrm{~L}$ stainless steel prepared by selective laser melting. J. Nucl. Mater. 470, 170-178 (2016)

6. J. Kell, J.R. Tyrer, R.L. Higginson, R.C. Thomson, Microstructural characterization of autogenous laser welds on $316 \mathrm{~L}$ stainless steel using EBSD and EDS. J. Microsc. 217(2), 167-173 (2005)

7. V.P. Kujanpää, S.A. David, C.L. White, Formation of hot cracks in austenitic stainless steel welds-solidification cracking. Weld. J. 65(8), 203s-212s (1986)

8. E. Assuncao, S. Williams, D. Yapp, Interaction time and beam diameter effects on the conduction mode limit. Opt. Lasers Eng. 50(6), 823-828 (2012)

9. J.A. Ramos, D.L. Bourell, J.J. Beaman, Surface over-melt during laser polishing of indirect-SLS metal parts. Mat. Res. Soc. Symp. Proc. 758, 53-61 (2002)

10. S. Katayama, Y. Kawahito, M. Mizutani, Elucidation of laser welding phenomena and factors affecting weld penetration and welding defects. Phys. Procedia 5, 9-17 (2010)

Publisher's Note Springer Nature remains neutral with regard to jurisdictional claims in published maps and institutional affiliations. 